\title{
SINGLE PHASE PWM RECTIFIER IN TRACTION APPLICATION
}

\author{
L’ubomír GRMAN - Martin HRAŠKO \\ — Jozef KUCHTA - Jozef BUDAY
}

\begin{abstract}
This research has been motivated by industrial demand for single phase PWM rectifier in traction application. This paper presents an advanced control structure design for a single phase PWM rectifier. The PWM rectifier is controlled to consume nearly sinusoidal current with power factor nearing to unity. The control structure consists of a DC-link voltage controller and a current controller implemented by a proportional- resonant controller using a fast phase angle and frequency estimator. The estimation algorithm is derived from the weighted least-squares estimation method. The feasibility of the proposed control structure is confirmed by experimental tests performed on designed laboratory prototype.
\end{abstract}

K e yw ords: rectifier, pulse width modulation, control algorithm, resonant control, phase angle estimation, traction application

\section{INTRODUCTION}

At the beginning of the 1970's, the research and development of electric traction schemes of an electric locomotive with the traction voltage $15 \mathrm{kV} / 16.7 \mathrm{~Hz}$ (Germany, Switzerland, Austria, Sweden, Norway) and $25 \mathrm{kV} / 50 \mathrm{~Hz}$ (France, Spain, etc) has been oriented almost exclusively to implementation of a three-phase induction motor as an electric traction motor which had replace a contact DC traction motor with series and separate excitation. Gradually, the traction AC single-phase voltage has been reduced by a traction vehicle transformer with voltage transfer which allows to generate a DC-link voltage for traction frequency converters to supply the three-phase induction traction motor (ITM) with nominal line-to-line voltage (approx. $2-2.2 \mathrm{kV}$ ). The marginal power of ITM directed to hundreds $\mathrm{kW}$, today the top locomotives has power about $1.2-1.6 \mathrm{MW}$. Use this power with four or six ITM in one vehicle requires that from traction line was consumed power with the power factor nearing to unity and minimal distortion of the traction voltage.

After extensive research and verification, it came to the conclusion that impulse rectifier referred to as "fourquadrant converter" is connected to secondary winding of the traction transformer. The power part of converter the most frequently consists the single-phase bridge like other converters makes it possible to transmission of electricity between AC and DC traction system - DC-link of traction frequency converters in both directions. Whereas dimension of the impulse 4Q-converter is pretty simple, the problem appears the control structure in all operating conditions of the vehicle for achieving the power factor nearing to unity. These issues and possible solutions are described in this paper.
In a single phase system, the reference of the line current is a $50 \mathrm{~Hz}$ AC signal under the steady state, and the current controller is required to track such an $\mathrm{AC}$ reference. There have been several control schemes for an $\mathrm{AC}$ tracking controller such as the hysteresis control methods, the predictive control methods, and so on [2], [14]. In this work is used the resonant control approach [4], [7-10] for an AC tracking controller. The proposed control scheme using the PR (Proportional-Resonant) controller that is capable of tracking a sinusoidal line current reference without an additional prediction or an extremely high control gain.

When electrical railway traction crosses over to the power section supplied by another voltage source, the amplitude and/or the phase angle of a source voltage may change in a step manner. In this case, the normal phase angle detector, such as a phase locked loop (PLL) and a lowpass (or notch) filter, typically generates a phase delay, results in a sluggish response, and causes some time critical machine to malfunction. In this work, a source voltage estimator is used based on the weighted least squares estimation (WLSE) method [9]. The proposed estimator provides the phase angle, the frequency, and the magnitude information of the source voltage's fundamental component without a delay.

\section{PWM RECTIFIER}

The rectifier controlled by pulse width modulation (PWM) consumes current of required shape, which is mostly sinusoidal. It works with a given phase displacement between the consumed current and the supply voltage. The power factor can also be controlled and there are minimal effects on the supply network.

* Electrotechnical Research and Projecting Company, j.s.c., Trenčianska 19, SK-018 51 Nová Dubnica, Slovakia, grman@evpu.sk, hrasko@evpu.sk, kuchta@evpu.sk, buday@evpu.sk 


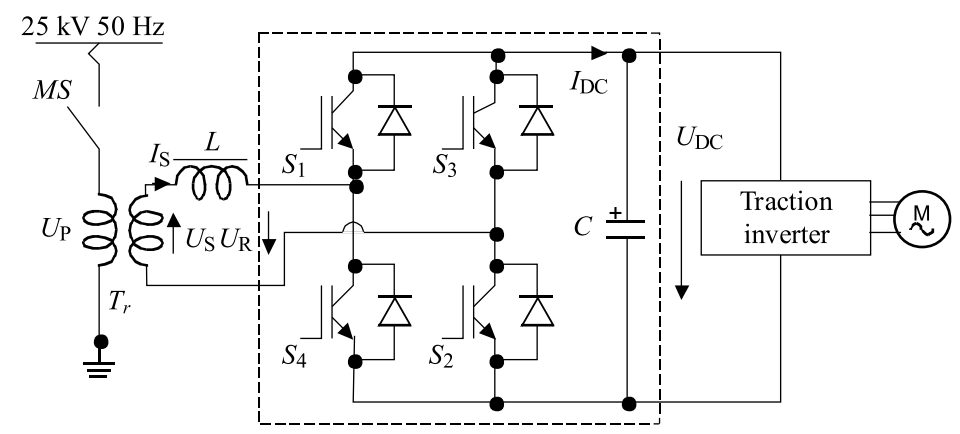

Fig. 1. Structure of a single phase PWM rectifier

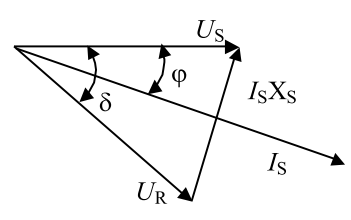

(a)

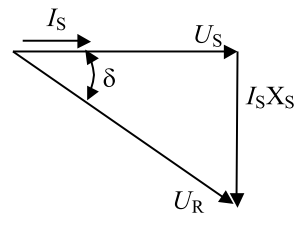

(b)

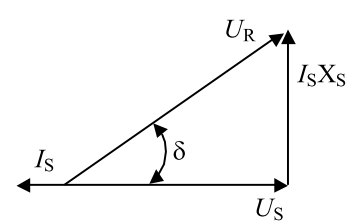

(c)
Fig. 2. Phase diagrams

The main features of PWM rectifiers are [5]:

- bi-directional power flow,

- nearly sinusoidal input current,

- regulation of input power factor to unity,

- low harmonic distortion of line current (THD below $5 \%)$

- adjustment and stabilization of DC link voltage (or current),

- reduced capacitor (or inductor) size due to the continuous current,

- properly operated under line voltage distortion and line frequency variations.

PWM rectifiers can be divided into two groups according to power circuit connection [1]:

voltage rectifiers (called boost rectifier - increases voltage): requires higher voltage on the DC side than the maximum value of the supply voltage. The rectified voltage on the output is smoother than the output voltage of the current type rectifier. They also require a more powerful microprocessor for their control. Output voltage lower than the voltage on input side can be obtained only with increased reactive power consumption.

current rectifiers (called buck rectifier - decreases voltage): the maximum value of the supply voltage must be higher than the value of the rectified voltage. The main advantage is that the rectified voltage is regulated from zero. They are suitable for work with DC loads (DC motors, current inverters).

The PWM single phase rectifier consists of 4 IGBTs connected in full bridge [12] is shown in Fig. 1.

The source power is supplied through a transformer $\mathrm{Tr}$ and the input inductance $L$. The output DC link voltage $U_{D C}$ is filtered by capacitor $C$ and fed into a 3-phase inverter that drives the traction. Supplied voltage $U_{S}$ and the voltage at the rectifier input $U_{R}$ are sinusoidal waveforms separated by the input inductance. Therefore the energy flow depends on the angle between these two phases. See the phase diagram in Fig. 2a [1], [5], [11].

The power transferred from the supply to the input terminals of the rectifier is

$$
P=\frac{U_{S} U_{R}}{X_{S}} \sin \delta=U_{S} I_{S} \cos \phi
$$

where

$U_{S}$ is RMS value of input supply voltage $(\mathrm{V})$,

$U_{R}$ RMS value of first harmonics consumed by $\mathrm{AC}$ rectifier input $(\mathrm{V})$,

$\delta$ phase displacement between phasors $U_{S}$ and $U_{R}(\operatorname{deg})$,

$X_{S}$ input inductor reactance at $50 \mathrm{~Hz}(\Omega)$,

$\phi$ power factor.

In order to make the rectified voltage constant the input and output powers must be balanced. Then as the phasor diagram in Fig. 2a shows

$$
\begin{aligned}
I_{S} \cos \phi & =U_{R} \frac{\sin \delta}{X_{S}} \\
I_{S} \sin \phi & =\frac{U_{S}-U_{R} \cos \delta}{X_{S}} .
\end{aligned}
$$

As long as the reactive power consumed is equal to zero the power factor is equal to unity. Therefore (2) and (3) can be adapted to

$$
\begin{aligned}
I_{S} X_{S} & =U_{R} \sin \delta, \\
U_{S} & =U_{R} \cos \delta .
\end{aligned}
$$




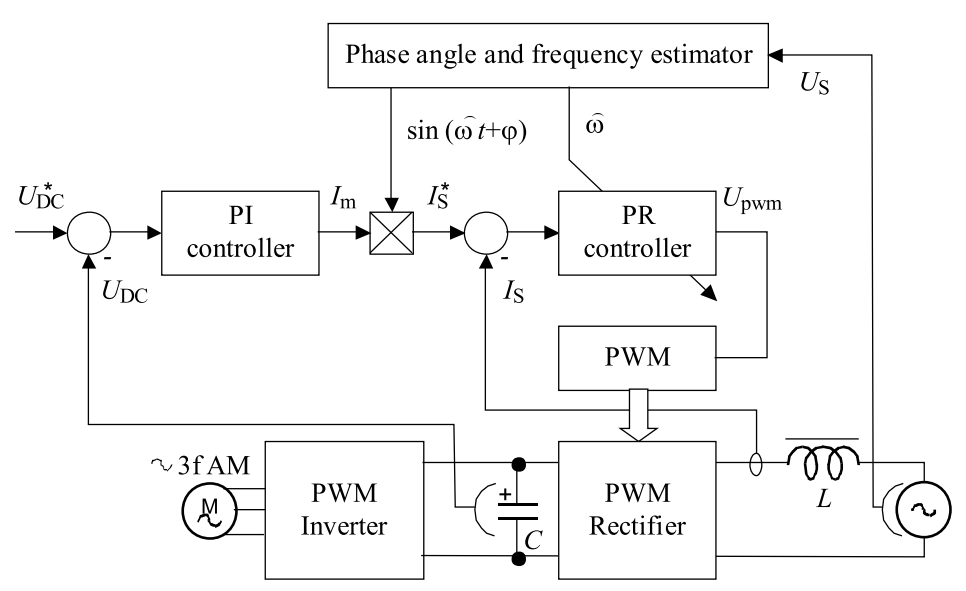

Fig. 3. Control structure of a single phase PWM rectifier

The phasor diagrams of the rectifier which works both as a rectifier and as an inverter are shown in Figs. $2 \mathrm{~b}$ and $2 \mathrm{c}$.

The aim is to control the rectifier in such a way that it consumes harmonical current from the supply network which is in phase with the supply voltage. This can be achieved by controlling the rectifier by pulse width modulation.

\section{PROPOSED CONTROL AND ESTIMATION ALGORITHM}

\subsection{Phase angle and frequency estimation}

The phase angle of a source voltage is used to calculate and control the flow of active/reactive power. The phase angle is a critical piece of information for the operation of most power conditioning equipment, such as pulse width modulation $\mathrm{AC} / \mathrm{DC}$ converter, uninterruptible power supplies (UPS), AC voltage compensators, static VAR compensators (SVC), active harmonic filters etc. In power conditioning equipment, the exact value of a positive sequence is needed to achieve the unity power factor and constant output voltage, whereas the exact value of a negative sequence is needed for unbalance compensation.

A fast phase angle and frequency estimator is presented, which is capable of estimating the phase angle and the frequency of the source voltage even under a highly distorted source voltage condition or sudden amplitude, phase angle, or frequency changing condition. The algorithm is derived from the weighted least squares estimation (WLSE) [8-10].

A single phase voltage $U_{S}$ is expressed such that

$$
U_{S}(t)=U_{m} \sin (\omega t+\varphi)=U_{d} \sin \omega t+U_{q} \cos \omega t
$$

where
$U_{m}$ is amplitude of source voltage $(\mathrm{V})$,

$\omega$ constant angular frequency $(\mathrm{rad} / \mathrm{s})$,

$\varphi$ phase angle (deg), $U_{d}=U_{m} \cos \varphi, U_{q}=U_{m} \sin \varphi$.

By applying the WLSE method to (6), the estimation $\hat{U}_{d}$ and $\hat{U}_{q}$ are obtained from $U_{S}$ such that

$$
\begin{array}{r}
\hat{\mathbf{x}}\left(t_{i}\right)=\hat{\mathbf{x}}\left(t_{i-1}\right)+\mathbf{R}\left(t_{i}\right)\left(U_{S}\left(t_{i}\right)-\mathbf{H}\left(t_{i}\right) \hat{\mathbf{x}}\left(t_{i-1}\right)\right), \\
i=1,2,3, \ldots
\end{array}
$$

where $\hat{\boldsymbol{x}}\left(t_{i}\right)=\left[\begin{array}{ll}U_{d}\left(t_{i}\right) & U_{q}\left(t_{i}\right)\end{array}\right]^{\top}$,

$$
\begin{aligned}
& \mathbf{H}\left(t_{i}\right)=\left[\begin{array}{ll}
\sin \omega t_{i} & \cos \omega t_{i}
\end{array}\right], \\
& \mathbf{R}\left(t_{i}\right)=\mathbf{P}\left(t_{i-1}\right) \mathbf{H}\left(t_{i}\right)^{\top}\left(1+\mathbf{H}\left(t_{i}\right) \mathbf{P}\left(t_{i-1}\right) \mathbf{H}\left(t_{i}\right)^{\top}\right)^{-1}, \\
& \mathbf{P}\left(t_{i}\right)=\lambda^{-1}\left(\mathbf{P}\left(t_{i-1}\right)-\mathbf{R}\left(t_{i}\right) \mathbf{H}\left(t_{i}\right) \mathbf{P}\left(t_{i-1}\right)\right),
\end{aligned}
$$

$\lambda \in(0,1)$ is the forgetting factor, initial conditions: $\hat{\mathbf{x}}\left(t_{0}\right)=\mathbf{0}, \mathbf{P}\left(t_{0}\right)=\gamma \mathbf{l} \in \Re^{2 \times 2}$, $\gamma>0$ is the initial covariance constant.

The noise immunity of the WLSE estimator can be increased by selecting a larger forgetting factor $\lambda$ and faster convergence can be achieved by choosing the larger $\gamma$.

The phase angles estimation is obtained from $\hat{U}_{d}$ and $\hat{U}_{q}$ such that

$$
\hat{\varphi}\left(t_{i}\right)=\operatorname{atan} 2\left(\hat{U}_{d}\left(t_{i}\right), \hat{U}_{q}\left(t_{i}\right)\right), \quad i=1,2,3, \ldots
$$

where atan 2 is the arc-tangent function.

The frequency information is quite important for phase angle estimation algorithm. The phase angle estimation algorithm can be extended to the estimation of $\omega$, when the frequency varies. When the frequency estimate $\hat{\omega}$ is not equal to the real frequency $\omega$ the estimated phase angle $\varphi$ varies such that

$\Delta \hat{\varphi}=\hat{\varphi}\left(t_{i}\right)-\hat{\varphi}\left(t_{i-1}\right)=(\omega-\hat{\omega})\left(t_{i}-t_{i-1}\right), \quad i=1,2,3, \ldots$ 
We can recognize that if $\Delta \hat{\varphi} \neq 0$, then there is a frequency estimation error. The basic idea for updating $\hat{\omega}$ is to employ a PI controller (10) so that $\Delta \hat{\varphi}$ is nullified

$$
\hat{\omega}\left(t_{i}\right)=\hat{\omega}\left(t_{0}\right)+K_{P f} e\left(t_{i}\right)+K_{I f} \sum_{j=2}^{i} e\left(t_{j}\right),
$$

where $e\left(t_{i}\right)=\hat{\varphi}\left(t_{i}\right)-\hat{\varphi}\left(t_{i-1}\right)$ is error,

$K_{P f}$ proportional gain,

$K_{I f}$ integral gain.

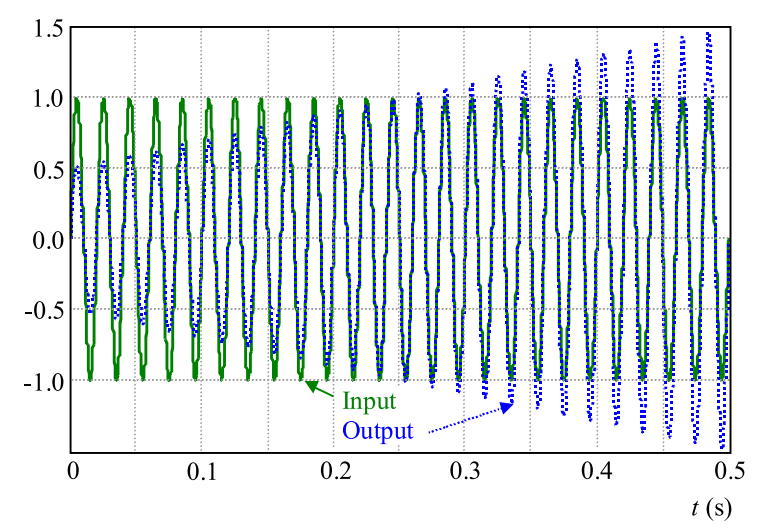

Fig. 4. Time domain response of the PR controller

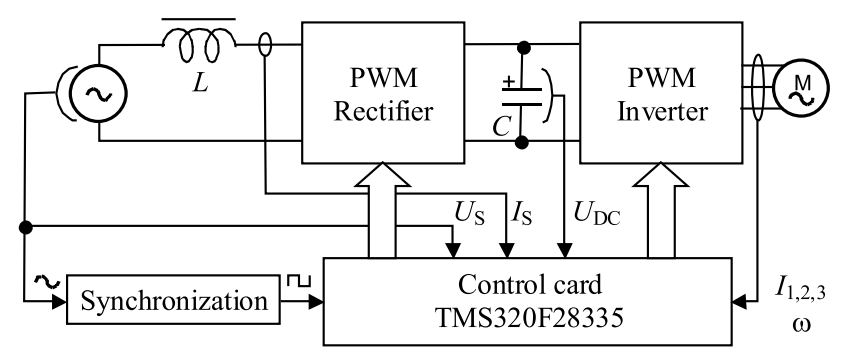

Fig. 5. Simplified block diagram of the PWM rectifier

The estimated source voltage $\hat{U}_{S}$ is then obtained as $\hat{U}_{S}\left(t_{i}\right)=\hat{U}_{d}\left(t_{i}\right) \sin \hat{\omega} t_{i}+\hat{U}_{q}\left(t_{i}\right) \cos \hat{\omega} t_{i}, \quad i=1,2,3, \ldots$

\subsection{Voltage and current controller}

The proposed control system consists of the DC-link voltage controller, the current controller, the phase angle estimator and the PWM generator [7], [9], see the structure in Fig. 3.

The DC-link voltage controller is implemented by using a conventional proportional-integral (PI) controller whose output is the amplitude of the current reference $I_{m}$ and transfer function is given by

$$
G_{P I}(s)=K_{P u}+\frac{K_{I u}}{s}
$$

where $K_{P u}$ and $K_{u I}$ are the proportional and the integral control gain, respectively.
The current reference $I_{s}^{*}$ is constructed by multiplying the synchronized signal with the source voltage: $I_{s}^{*}=$ $I_{m} \sin (\hat{\omega} t+\varphi)$. The sinusoidal current reference $I_{s}^{*}$ is fed into the current controller.

The current controller is constructed based on the proportional-resonant (PR) controller whose transfer function [4] is given by

$$
G_{P R}(s)=K_{P i}+\frac{2 K_{R i} s}{s^{2}+\omega^{2}}
$$

where $K_{P i}$ and $K_{R i}$ are the proportional and the resonant control gain, respectively, $\omega$ is the fundamental angular frequency of the source current $(\mathrm{rad} / \mathrm{s})$.

The time domain response of the resonant controller when $K_{P i}=0.5, K_{R i}=2, f=50 \mathrm{~Hz}$ with sinusoidal input $\sin \omega t$ is shown in Fig. 4 .

It can be seen from Fig. 4 that the gain of the transfer function (13) is infinity at $\omega$, the output is in phase with the input signal, but the amplitude is amplified with time. With the resonant control method, one can track the high frequency sinusoidal current reference without increasing the switching frequency nor adopting an extremely large control gain.

For a proper operation of PWM rectifier a minimum DC-link voltage is required [1], [3], [5]. Generally, it can be determined by the maximum value of the supply voltage $U_{S}$ that is

$$
U_{D C \min }>U_{S \max } \text { or } U_{D C \min }>\sqrt{2} U_{S(R M S)} .
$$

If this condition is not fulfilled, the full control of the input current is not possible. Defining the natural DClink voltage value (as it is possible to obtain in case of not operating transistors) the freewheeling diodes constitute a standard diode bridge. Typically, the reference value for the controlled DC-link voltage should be chosen about $10 \%$ above the natural DC-link voltage. The unity power factor required for PWM rectifier operation can be obtained in case of

$$
U_{R}^{2}=U_{S}^{2}+U_{L}^{2}
$$

The voltage drop across the inductor $U_{L}$ depends on reactance $L$ of the inductor at the input frequency and on the input current $I_{S}$. The magnitude of the switching voltage vectors depends on the DC-link voltage level [5].

\section{EXPERIMENTAL RESULTS}

The control structure of a single phase PWM rectifier has been confirmed by experimental tests performed on designed laboratory prototype. Block diagram of the PWM rectifier control system is shown in Fig. 5. The power part is realized by four IGBT transistors and the 

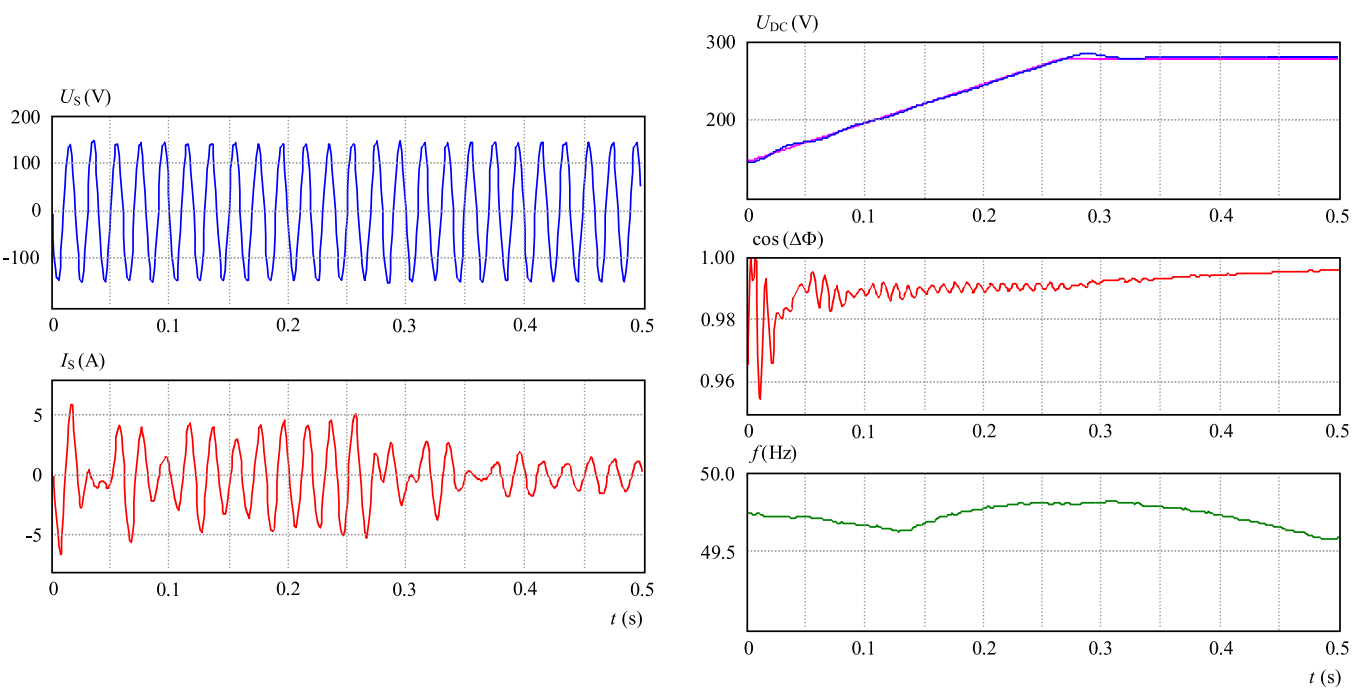

(a)

Fig. 6. Transient responses when DC-link voltage changes gradually with no-load; a) input voltage and current, b) DC-link voltage, power factor and frequency
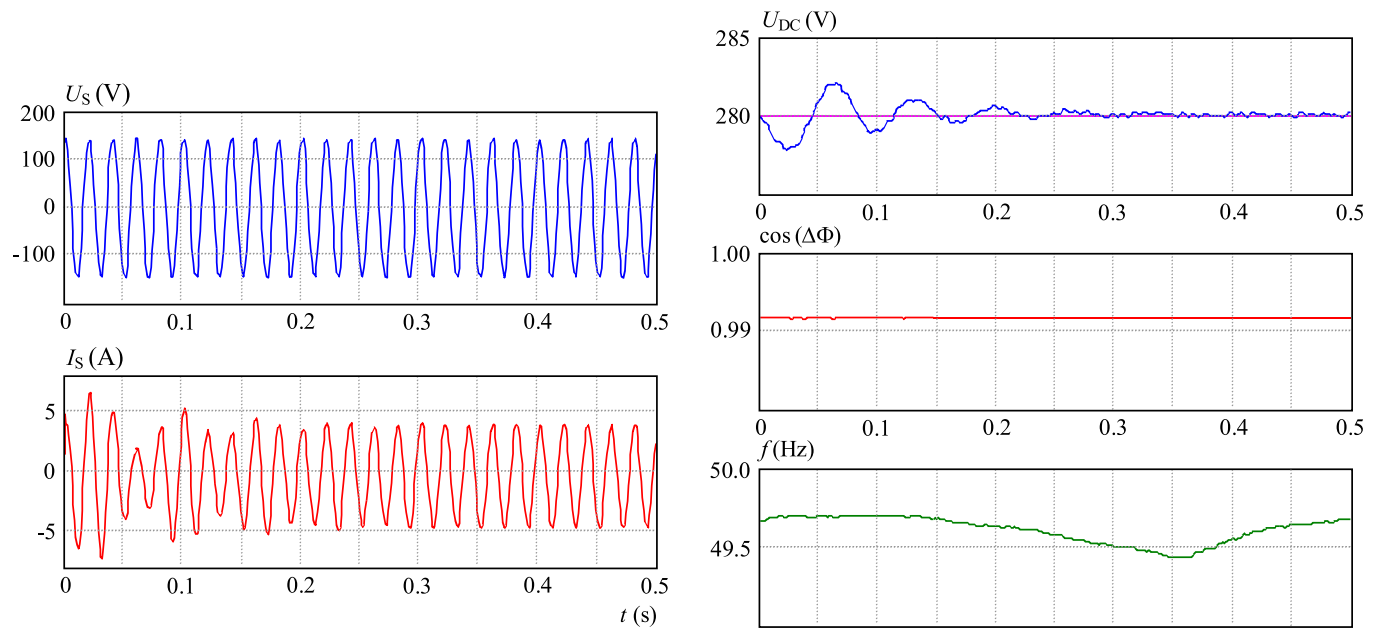

(a)

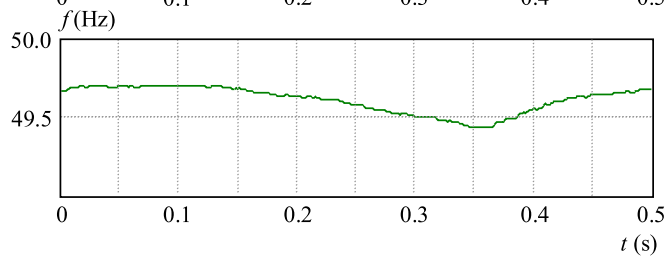

(b)

Fig. 7. Transient responses (PWM rectifier and inverter): no-load AM; a) input voltage and current, b) DC-link voltage, power factor and frequency

digital signal processor TMS320F28335 (Texas Instruments) was chosen as controller and for computing WLSE algorithm.

In order to keep proper function of control algorithm, it is necessary to synchronize the control structure with power grid voltage curve. When supposing purely sinusoidal voltage curve, we only need to know the moments when the voltage curve crosses the zero axes (moments of polarity change) and the voltage polarity in every halfperiod. The easiest way to follow this condition is to convert sinusoidal curve (power grid voltage) into the square shape with logical levels of 0 and $3 \mathrm{~V}$, otherwise log. 0 and $\log .1$ as well. Log. 0 corresponds to negative half-wave, $\log .1$ to positive. Signal edges indicate the zero crossings. The DSP processor these zero crossing by means of ex- ternal interrupt. The polarity is evaluated from the zero crossing direction — rising or falling edge [6].

Experiments were performed with the parameters of controllers given in Tab. 1. The switching frequency was set to be $5 \mathrm{kHz}$ and the parameters of the phase angle estimator were selected such that $\lambda=0.9999$ and $\gamma=$ 0.02 .

Table 1. Parameter list of the controllers

\begin{tabular}{cccccc}
\hline \multicolumn{3}{c}{ Parameters of the controllers: } \\
frequency & \multicolumn{2}{c}{ voltage } & \multicolumn{2}{c}{ current } \\
\hline$K_{P f}$ & 20 & $K_{P u}$ & 1.15 & $K_{P i}$ & 0.4 \\
$K_{I f}$ & 1000 & $K_{I u}$ & 0.008 & $K_{R i}$ & 0.012 \\
\hline
\end{tabular}



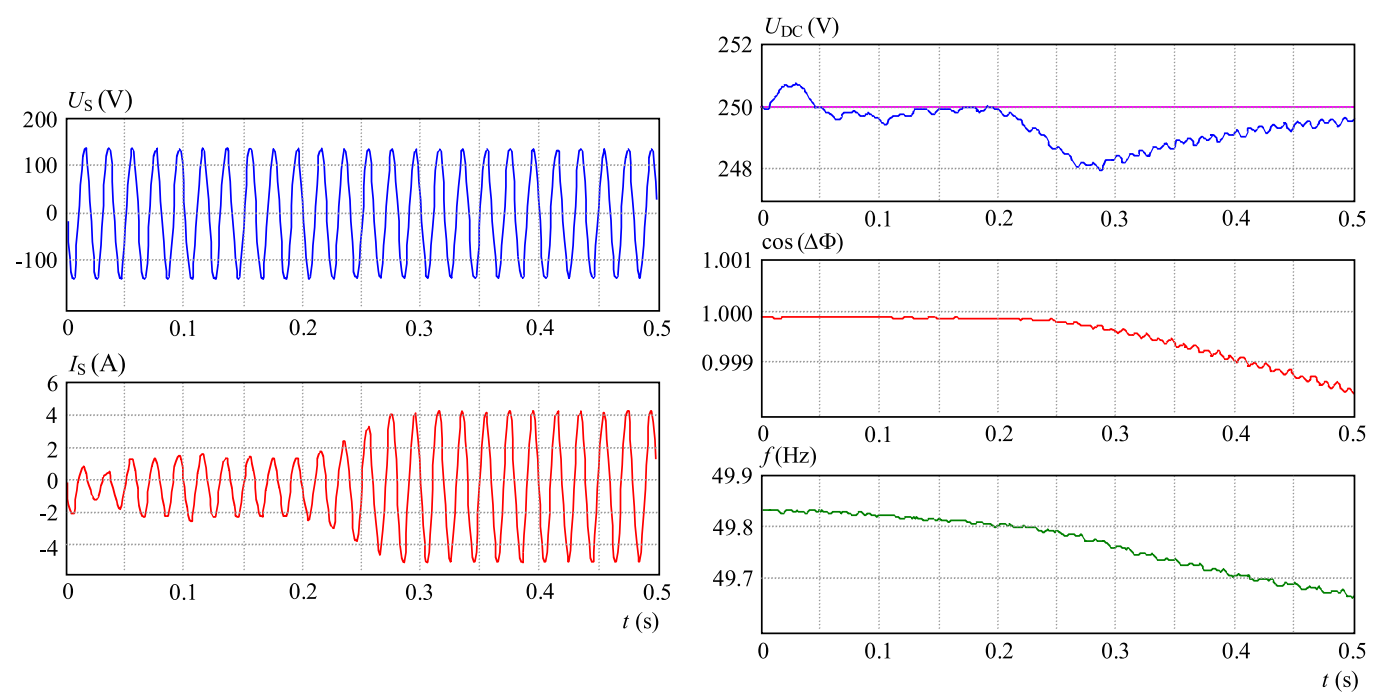

(a)

(b)

Fig. 8. Transient responses (PWM rectifier and inverter): short-circuit AM in $t_{s}=0.2 \mathrm{~s}$; a) input voltage and current, b) DC-link voltage, power factor and frequency
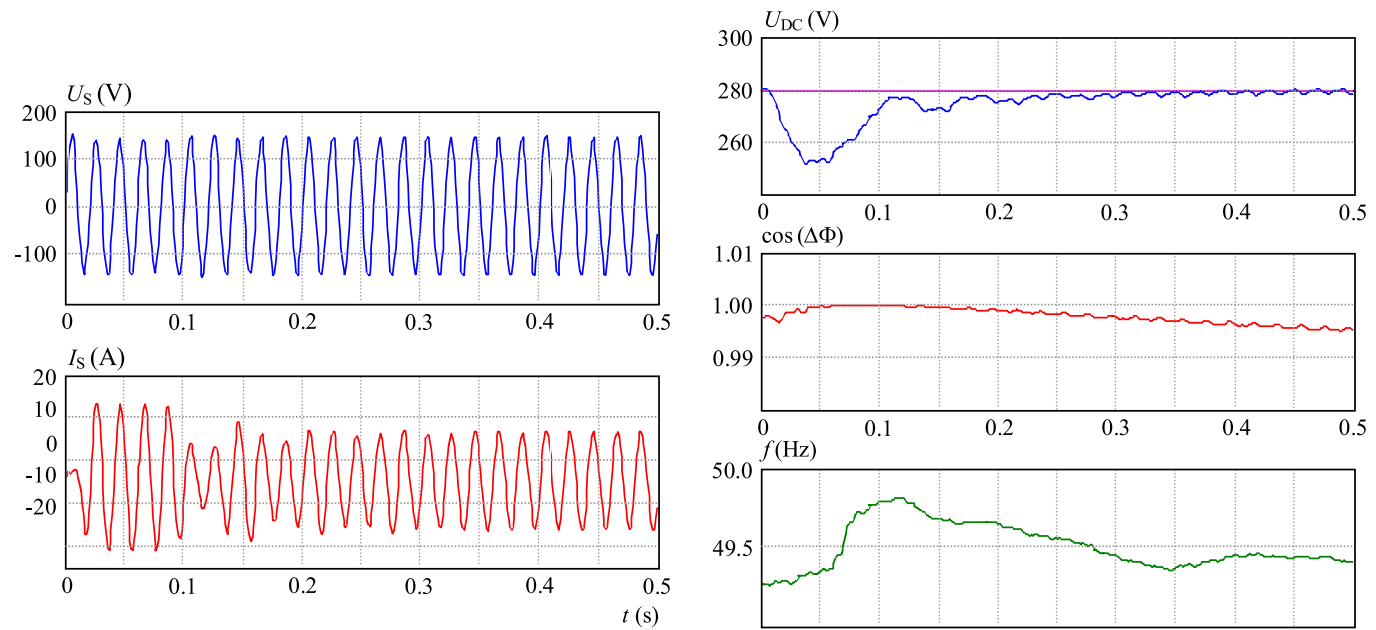

(a)

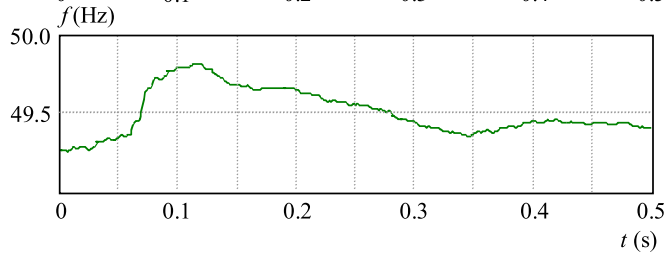

(b)

Fig. 9. Transient responses (Transient responses (PWM rectifier and inverter): load on AM; a) input voltage and current, b) DC-link voltage, power factor and frequency

The conditions for test were: $U_{S m}=145 \mathrm{~V}, U_{D C}=$ $280 \mathrm{~V}$, the input inductor $L=35 \mathrm{mH}$, the DC link capacitor $C=3000 \mu \mathrm{F}$. The parameters of asynchronous motor were: $P_{n}=1.5 \mathrm{~kW}, U_{n}=230 \mathrm{~V} / 400 \mathrm{~V}, f=50 \mathrm{~Hz}$, $n=705 \mathrm{rpm}, M_{m}=20 \mathrm{Nm}$ and number of poles $p=8$.

The experimental tests of a single phase PWM rectifier has been performed by asynchronous motor (AM) with no-load, short-circuit and load on. The asynchronous motor has been loaded on by the synchronous linear motor with permanent magnets (SMPM). The results of experimental tests are shown in the following figures.

Figure 6 shows the experimental results of transient responses (PWM rectifier) when DC-link voltage changes gradually and no-load is attached. The input current surge is reduced by the ramp of reference value of DClink voltage. The required value $U_{D C}$ is reached in time
$0.25 \mathrm{~s}$. The steady-state value of power factor is 0.995 and the average value of frequency is $49.74 \mathrm{~Hz}$. The results of transient responses (PWM rectifier and PWM inverter) when AM has no-load is shown in Fig. 7. In this case the value of power factor is 0.992 and the average value of frequency is $49.62 \mathrm{~Hz}$. Figure 8 shows the experimental results of transient responses (PWM rectifier and PWM inverter) when short-circuit is applied on the AM in time $t_{s}=0.2 \mathrm{~s}$. Drop of DC-link voltage is about $-0.8 \%(248 \mathrm{~V})$ from reference value $(250 \mathrm{~V})$. The steady-state value of power factor is 0.992 and the average value of frequency is $49.77 \mathrm{~Hz}$. The results of transient responses when $\mathrm{AM}$ is loaded on moment $4 \mathrm{Nm}$ by SMPM is shown in Fig. 9. Drop of DC-link voltage is about $-10.4 \%(251 \mathrm{~V})$ from reference value $(280 \mathrm{~V})$ and the steady-state value of power factor is 0.995 . 


\section{CONCLUSION}

This paper presented an advanced control structure design for a single phase PWM rectifier. The control structure consists of a proportional-resonant controller using a fast phase angle and frequency estimator. The estimation algorithm is derived from the weighted leastsquares estimation method.

The PWM rectifier can perform well in many applications, for example as an active filter or as an input rectifier for an indirect frequency converter. This application is useful mainly in traction, where the $\mathrm{AC}$ voltage from the trolley wire is first rectified, and the traction inverters and also other auxiliary converters are fed from the output of the rectifier. A traction vehicle equipped with a PWM rectifier does not consume reactive power, will not load the supply network with harmonics and can recuperate. The proposed control structure is confirmed by experimental tests performed on designed laboratory prototype.

\section{Acknowledgment}

This work was supported by the Slovak Research and Development Agency under the contract No. APVV0530-07.

\section{REFERENCES}

[1] BAUER, J.: Single-Phase Pulse Width Modulated Rectifier, Acta Polytechnica 48 No. 3 (2008), 84-87.

[2] CICHOWLAS, M.-KAZMIERKOWSKI, M.: Comparison of Current Control Techniques for PWM Rectifiers, ISIE 2001, l'Aquila, Italy.

[3] JAVUREK, J.-KOPECKY, M.: Pulse Rectifier: Input Circuit of Three-Systems Locomotive, AT\&P journal No. 2 (2005), 40-41. (in Czech)

[4] KULKA, A.-UNDELAND, T.-VAZQUEZ, S.-FRANQUELO, L. G.: Stationary Frame Voltage Harmonic Controller for Standalo Power Generation, EPE 2007 Conference Alborg, Danmark, 2007.

[5] LETTLE, J-DOLECEK, R. : EMC Increasing of PWM Rectifier in Comparison with Classical Rectifier, Radioengineering 17 No. 4 (2008), 93-100.

[6] MiCHALIK, J.-MOLNAR, J.-PEROUTKA, Z.: Single Phase Current-Source Active Rectifier for Traction: Control System Design and Practical Problems, 6th International Conference "LEKTRO 2006", Žilina, Slovakia, May 23-24, 2006.

[7] SATO, Y.-ISHIZUKA, T.-NEZU, K.-KATAOKA, T. : A New Control Strategy for Voltage-Type PWM Rectifiers to Realize Zero Steady-State Control Error in Input Current, IEEE Transactions on Industry Applications 34 No. 3 (1998), 480-486.

[8] SONG, H. S.-KEIL, R.-MUTSCHLER, P.-WEEM, J.NAM, K. : Advanced Control Scheme for a Single-Phase PWM Rectifier in Traction Application, IEEE Industry Application Conference, 2003, pp. 1558-1565.

[9] SONG, H. S.-NAM, K.: Instantaneous Phase-Angle Estimation Algorithm under Unbalanced Voltage-Sag Conditions, IEE
Proceedings Generation, Transmission \& Distribution 147 No. 6 (2000), 409-415.

10] SONG, H. S.-NAM, K.-MUTSCHLER, P.: Very Fast Phase Angle Estimation Algorithm for a Single-Phase System having Sudden Phase Angle Jumps., IEEE Industry Application Conference (2002), 925-931.

11] THIYAGARAJAH, K.-RANGANATHAN, V. T.-RAMAKRISHNA IYENGAR, B. S.: A High Switching Frequency IGBT PWM Rectified Inverter System for AC Motor Drives Operating from Single Phase Supply. IEEE Transactions on Power Electronics.

12] VENKATESh, V.-RAO, S.-GUPtA, B. S.-RANGANATHAN, V. T. : Single Phase Front End Converter for Traction Drive, IE(I) Journal-EL 87 (2006).

Received 10 October 2010

L'ubomr Grman (Ing, PhD) was born in Topol'čany, Slovakia, in 1978. He graduated from the Faculty of Electrical Engineering and Information Technology, Slovak University of Technology, Bratislava, in 2002. He received PhD degree in Automation and Control at the same university, in 2005. He worked as research worker at Institute of Control and Industrial Informatics from 2005 to 2007. At present he is a research and development engineer at Electrotechnical Research and Projecting Company in Nová Dubnica, Slovakia. The main field of his research and activities are control structure design and their implementation to digital signal processors.

Martin Hraško (Ing, PhD) was born in 1977. He received $\mathrm{PhD}$ degree (2006) in power electronics, specializations electric drives from the University of Žilina. Since graduating, he has worked as R\&D engineer of control systems in Electrotechnical Research and Projecting Company (EVPU j.s.c), Nova Dubnica, Slovakia. His research interests include electric drives, power electronics and digital control.

Jozef Kuchta (Assoc Prof, Ing, PhD) was born in 1948. He received PhD degree from the Faculty of Electrical Engineering, Slovak Technical University, in 1983. He was appointed Associate Professor in the field of Power Electrical Engineering at the Faculty of Electrical Engineering, University of ilina (EF U), in 2008. From 1971 he worked as assistant professor at the EF ŽU in Žilina and from 1977 as leader of research in the field of Electrical Machines and Drives in Electrotechnical Research and Projecting Company (EVPÚ j.s.c). His main research interests are special electric machines, a new magnetic materials and components of advanced electric and diesel-electric locomotives.

Jozef Buday (Assoc Prof, Ing, PhD) was born in 1951. He received $\mathrm{PhD}$. degree from the Faculty of Electrical Engineering, University of Žilina, in 1991. He was appointed Associate Professor at the same faculty, in 2006. He worked in the field of power electronics, automation and mechatronics. At present he is managing director and R\&D department manager in Electrotechnical Research and Projecting Company (EVP j.s.c). He is laureate of many awards at home and abroad for building of testing laboratories, member of several commissions in department and government level. 